\title{
ARTHROSCOPIC TREATMENT OF ELBOW STIFFNESS
}

Luis Alfredo Gómez Vieira ${ }^{1}$, Fabio Farina Dal Molin², Adalberto Visco³, Luis Filipe Daneu Fernandes ${ }^{4}$, Murilo Cunha Rafael dos Santos ${ }^{5}$, Nivaldo Souza Cardozo Filho ${ }^{6}$, Nicolas Gerardo Gómez Cordero’

\section{ABSTRACT}

Objective: To present the arthroscopic surgical technique and the evaluation of the results from this technique for treating elbow stiffness. Methods: Between April 2007 and January 2010, ten elbows of ten patients with elbow stiffness underwent arthroscopic treatment to release the range of motion. The minimum follow-up was 11 months, with an average of 27 months. All the patients were male and their average age was 32.8 years (ranging from 22 to 48 years). After the arthroscopic treatment, they were followed up weekly in the first month and every three months thereafter. The clinical evaluation was made using the criteria of the University of California at Los Angeles (UCLA). Results: All the patients were satisfied with the results from the arthroscopic treatment. The average UCLA score was 33.8 points. Conclusion: Arthroscopic treatment for elbow stiffness is a minimally invasive surgical technique that was shown to be efficient for treating this complication.

Keywords - Elbow/surgery; Arthroscopy/methods; Range of Motion, Articular

\section{INTRODUCTION}

Elbow stiffness may result from a variety of causes, such as acute or chronic trauma, spasticity, heterotopic ossification, coma, burns, free bodies, synovitis and osteophytes in the proximal ulna, among others $^{(1-4)}$. It is observed in 3 to $6 \%$ of patients who suffer a supracondylar fracture and in 33 to $100 \%$ of patients who undergo surgical procedures to treat fractures of the proximal radial neck ${ }^{(5,6)}$.

However, if nonsurgical treatment is instituted early on, with physiotherapy and dynamic bracing, for example, this may result in improvement of the range of motion of the elbow ${ }^{(7,8)}$.
Equally, if conservative treatment fails, several surgical techniques are capable of releasing the elbow contractures $^{(9-13)}$.

The American Academy of Orthopaedic Surgeons (AAOS) has defined the normal range of motion (ROM) of the elbow as flexion from $0^{\circ}$ to $146^{\circ(14)}$. On the other hand, Morrey et $\mathrm{al}^{(15)}$ demonstrated that $90 \%$ of all activities of daily living can be accomplished with $\mathrm{ROM}$ from $30^{\circ}$ to $130^{\circ}$.

Thus, the indications for surgical treatment may relate to situations of elbow extension of less than $30^{\circ}$, painful end extension of less than $30^{\circ}$ or elbow contractures of less than $30^{\circ}$ of extension that impede certain functional demands ${ }^{(16)}$.

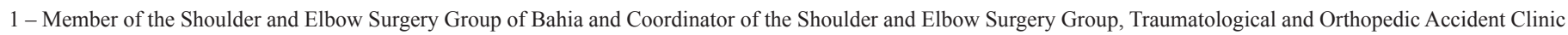
(CATO), Salvador, Bahia, Brazil.

2 - Orthopedic Surgeon at Hospital Moinhos de Vento, Porto Alegre, RS, Brazil.

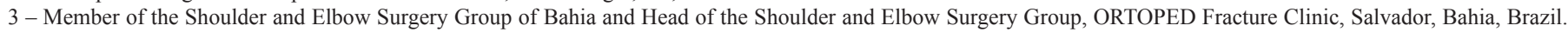

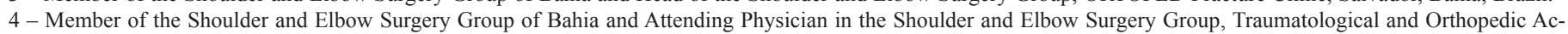
cident Clinic (CATO), Salvador, Bahia, Brazil.

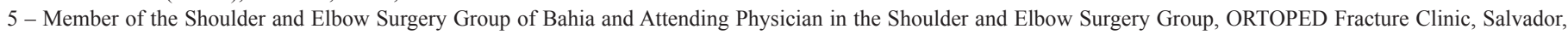
Bahia, Brazil.

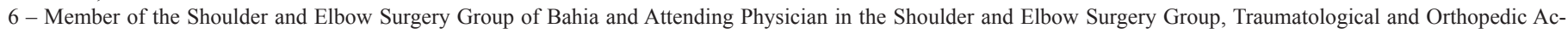
cident Clinic (CATO), Salvador, Bahia, Brazil

7 - Orthopedic Surgeon at the Traumatological and Orthopedic Accident Clinic (CATO), Salvador, Bahia, Brazil.

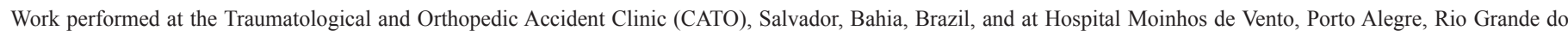
Sul, Brazil.

Correspondence: Avenida Anita Garibaldi, 1.133, Ondina - 40210-070 - Salvador, Bahia, Brasil. - E-mail: gomezvieira@hotmail.com

Work received for publication: June 07, 2010; accepted for publication: March 21, 2011.

The authors declare that there was no conflict of interest in conducting this work 
The purpose of the present study was to assess the results obtained from the arthroscopic surgical technique for treating elbow stiffness.

\section{METHODS}

Between April 2007 and January 2010, ten elbows of ten patients underwent arthroscopic treatment for elbow stiffness and reassessment. The operations were carried out by the Shoulder and Elbow Surgery Group of Bahia, at the Traumatological and Orthopedic Accident Clinic (CATO) and at Hospital Moinhos de Vento, Porto Alegre, RS, and were evaluated after receiving approval from the institutions' ethics committees.

The length of follow-up ranged from 11 to 37 months, with a mean of 27 months. The patients' mean age was 32.8 years, ranging from 22 to 48 years of age. All the patients were male (Table 1).

Table 1 - Data on patients.

\begin{tabular}{c|c|c|c|c}
\hline $\begin{array}{c}\text { Patient } \\
\text { number }\end{array}$ & Sex & Age & UCLA & $\begin{array}{c}\text { Postoperative } \\
\text { follow-up } \\
\text { (months) }\end{array}$ \\
\hline 1 & Male & 32 years & 33 & 37 \\
\hline 2 & Male & 28 years & 34 & 34 \\
\hline 3 & Male & 36 years & 34 & 24 \\
\hline 4 & Male & 48 years & 35 & 24 \\
\hline 5 & Male & 22 years & 35 & 13 \\
\hline 6 & Male & 25 years & 31 & 30 \\
\hline 7 & Male & 48 years & 32 & 26 \\
\hline 8 & Male & 24 years & 34 & 18 \\
\hline 9 & Male & 40 years & 35 & 17 \\
\hline 10 & Male & 25 years & 35 & 14 \\
\hline
\end{tabular}

Source: DOT-CATO and Hospital Moinhos de Vento.

UCLA = University of California at Los Angeles method for assessing postoperative results.

With regard to pronation /supination, all the patients maintained their functional ROM, and none of them presented any major limitation other than the compromised flexion-extension (mainly extension). The cause or origin of the elbow stiffness varied, with predominance of traumatic etiology, and the patients' preoperative $\mathrm{ROM}$ ranged from $30^{\circ}$ to $60^{\circ}$ (Table 2).

The patients were referred for physiotherapy procedures and were released for activities of daily living as soon as possible, which was around the second postoperative day, according to their pain threshold. Thus, the importance of early mobility was empha-
Table 2 - Data on patients.

\begin{tabular}{|c|c|c|c|c|}
\hline $\begin{array}{l}\text { Patient } \\
\text { number }\end{array}$ & Cause/Origin & $\begin{array}{c}\text { ROM } \\
\text { (extension) } \\
\text { Before } \\
\text { operation }\end{array}$ & $\begin{array}{c}\text { ROM } \\
\text { (extension) } \\
\text { After } \\
\text { operation }\end{array}$ & $\begin{array}{l}\text { ROM } \\
\text { gain }\end{array}$ \\
\hline 1 & Degenerative & $40^{\circ}$ & $15^{\circ}$ & $25^{\circ}$ \\
\hline 2 & Traumatic & $40^{\circ}$ & $10^{\circ}$ & $30^{\circ}$ \\
\hline 3 & Osteochondromatosis & $35^{\circ}$ & $0^{\circ}$ & $35^{\circ}$ \\
\hline 4 & Traumatic & $30^{\circ}$ & $0^{\circ}$ & $30^{\circ}$ \\
\hline 5 & Traumatic & $35^{\circ}$ & $0^{\circ}$ & $35^{\circ}$ \\
\hline 6 & Traumatic & $60^{\circ}$ & $15^{\circ}$ & $45^{\circ}$ \\
\hline 7 & Rheumatic & $40^{\circ}$ & $10^{\circ}$ & $30^{\circ}$ \\
\hline 8 & Traumatic & $45^{\circ}$ & $10^{\circ}$ & $35^{\circ}$ \\
\hline 9 & Traumatic & $55^{\circ}$ & $0^{\circ}$ & $55^{\circ}$ \\
\hline 10 & Traumatic & $30^{\circ}$ & $0^{\circ}$ & $30^{\circ}$ \\
\hline
\end{tabular}

sized. The patients were followed up every week for the first month after the arthroscopic procedure, and then every month for the first three months and every three months thereafter.

The method chosen for clinical assessments on the patients after the operation was based on the UCLA criteria (University of California at Los Angeles) ${ }^{(17)}$.

\section{SURGICAL TECHNIQUE}

Surgery was performed in all cases with the patient positioned in lateral decubitus, under general anesthesia and plexus block (Figure 1). For all the patients, we used a pneumatic tourniquet applied to the "root" of the limb, and an infusion pump at an atmospheric pressure of $30 \mathrm{mmHg}$.

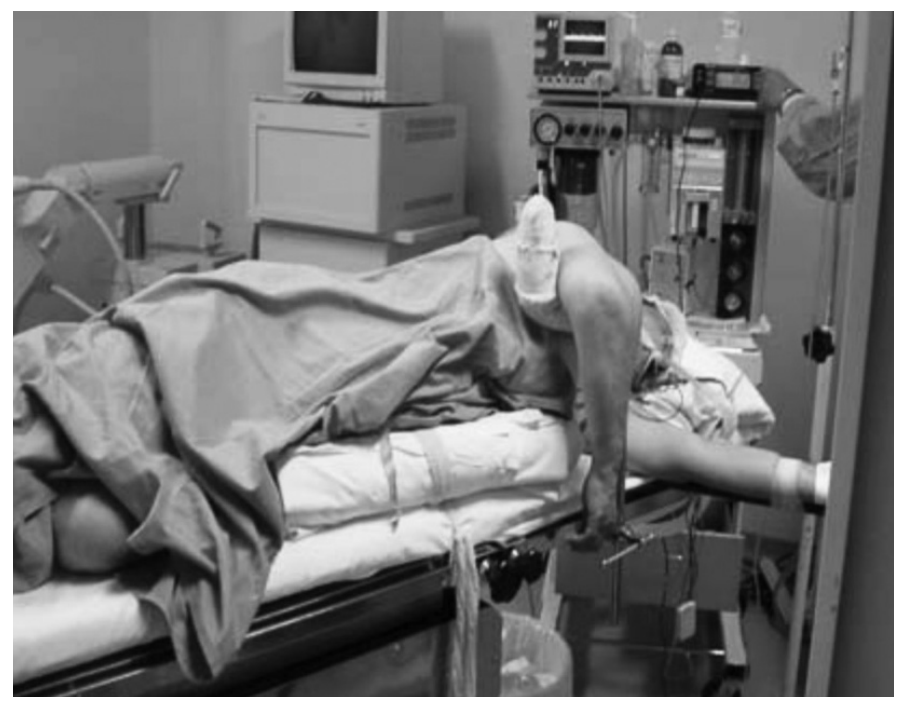

Figure 1 - Positioning of the patient in lateral decubitus. 
We started to access the joint through an anterolateral portal that was constructed $2 \mathrm{~cm}$ anteriorly and $2 \mathrm{~cm}$ distally to the lateral epicondyle (Figure 2). The joint capsule was distended using $15 \mathrm{ml}$ of saline solution (Figure 3). After introducing the optical device through the anterolateral portal, we then inspected the anterior region of the joint. By using the "inside out" technique, with placement of a Steinmann wire from a cannula positioned laterally and brought to the exterior medially, we constructed an anteromedial portal safely, without the risk of compromising the ulnar nerve (Figures 4 and 5).

With these two portals established, the procedure of joint release could begin. The optical device was kept in the anterolateral portal and the instrumentation was done through the anteromedial portal (Figure 6). We used a soft-tissue resection blade (shaver), generally with a diameter of $5 \mathrm{~mm}$, to remove the synovium from the anterior joint capsule of the stiff elbow. Whenever possible, we created a proximal access portal, $1 \mathrm{~cm}$ anteriorly and proximally to the

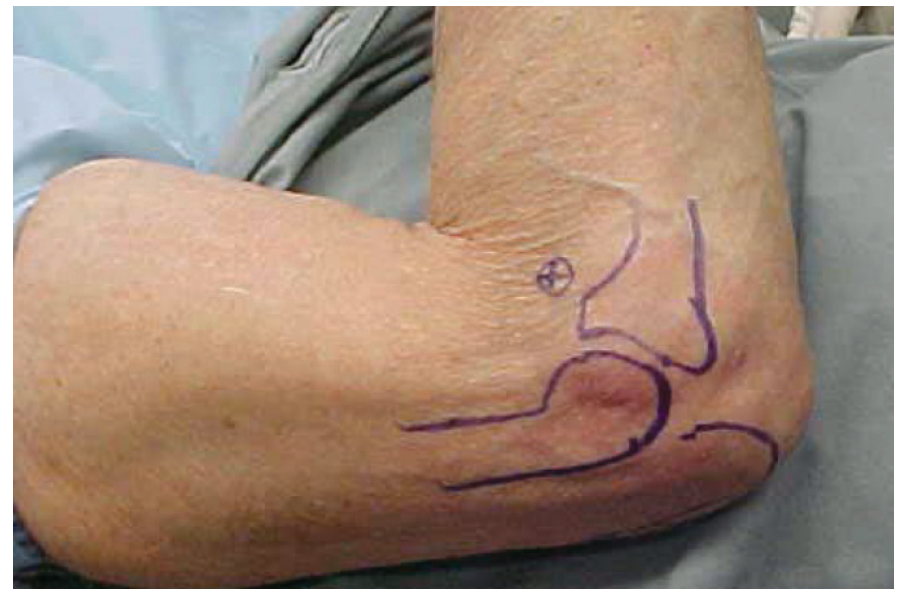

Figure 2 - Anterolateral portal.

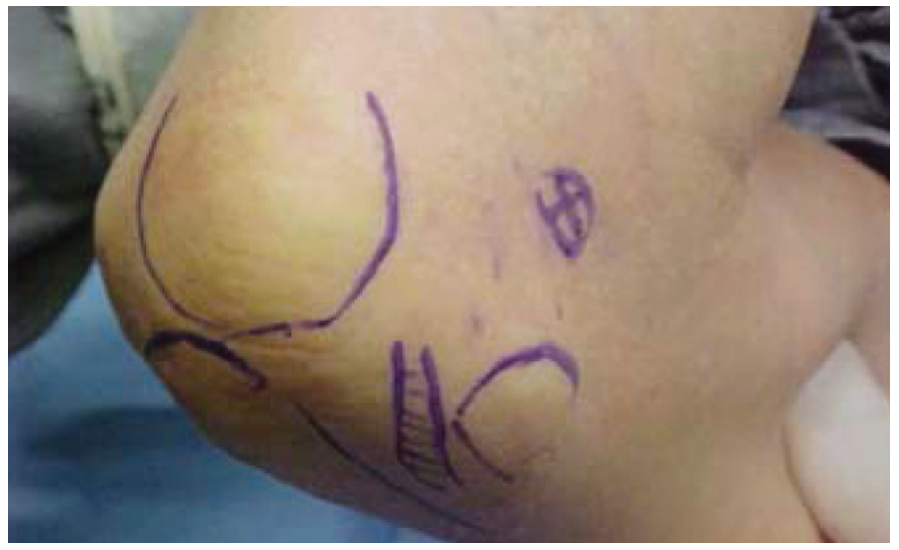

Figure 3 - Distention of the capsule using saline solution. anterolateral portal, through which the assistant surgeon introduced a snout-like spacer, in an attempt to push away the anterior soft tissue from the joint capsule (Figure 7).

Upon opening the anterior joint capsule, we started to perform capsulectomy using a basket-like instrument that was slid distally to proximally and medially to laterally, as far as the level of the head of the radius.

At this moment, we inverted the working portals so that the radial nerve could be dissected and the anterior capsulectomy could be completed, through the anterolateral portal. The ROM of the elbow was then tested.

If it was observed that there was still some limitation of ROM, we began posterior capsulectomy through the posterocentral portal (directly into the olecranon fossa), the superior posterolateral portal (1 $\mathrm{cm}$ proximally and $1 \mathrm{~cm}$ laterally to the posterocentral portal) and the inferior posterolateral portal ( $1 \mathrm{~cm}$ distally and $1 \mathrm{~cm}$ laterally to the posterocentral portal (Figure 8).

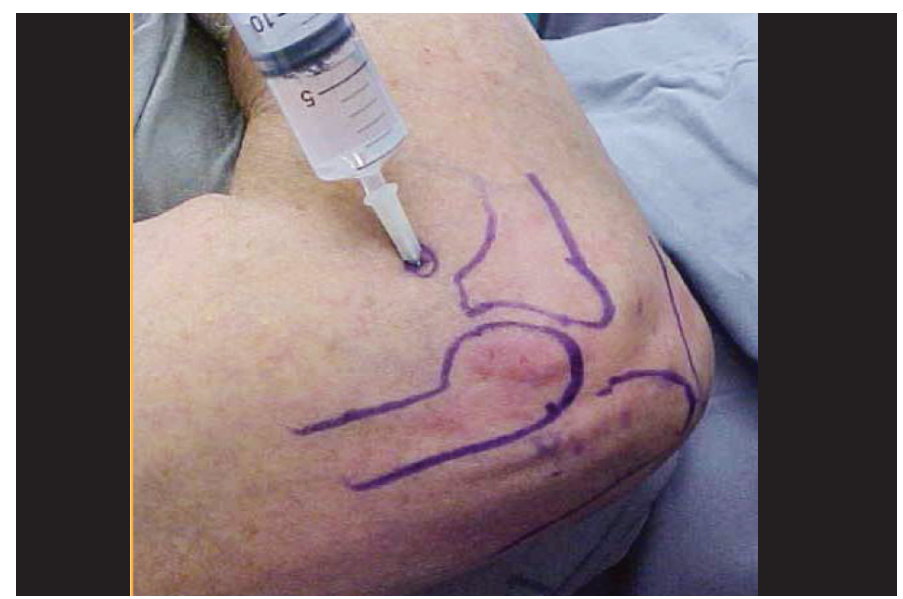

Figure 4 - Anteromedial portal.

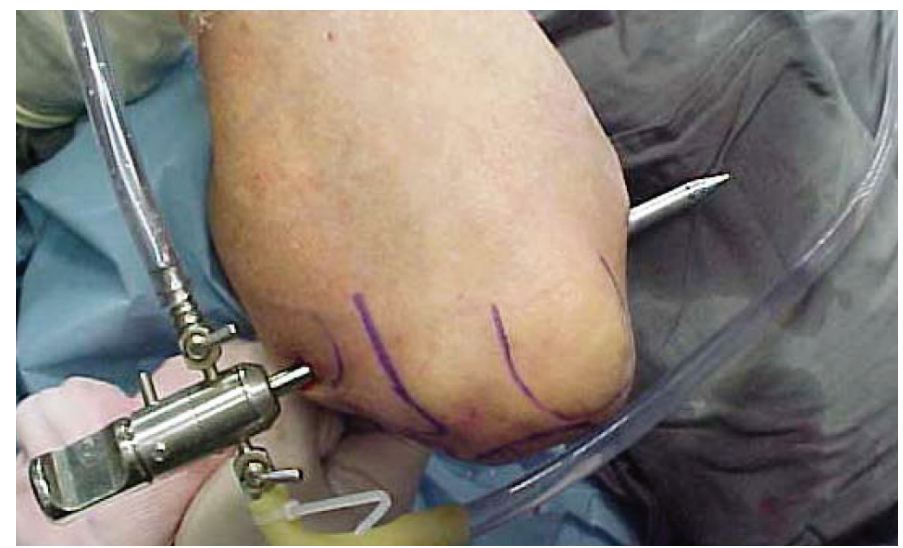

Figure 5 - Introduction of trochanter, laterally to medially. 


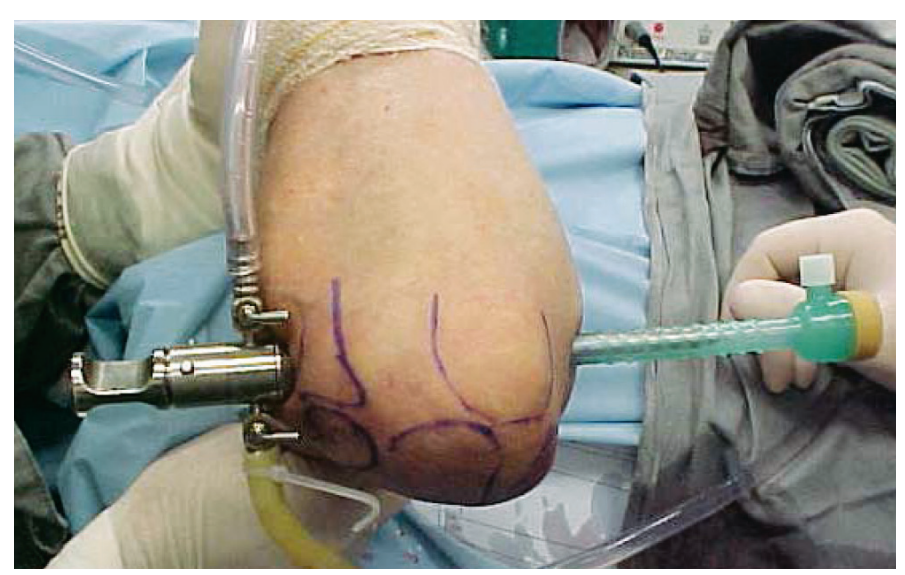

Figure 6 - Introduction of medial cannula through trochanter.

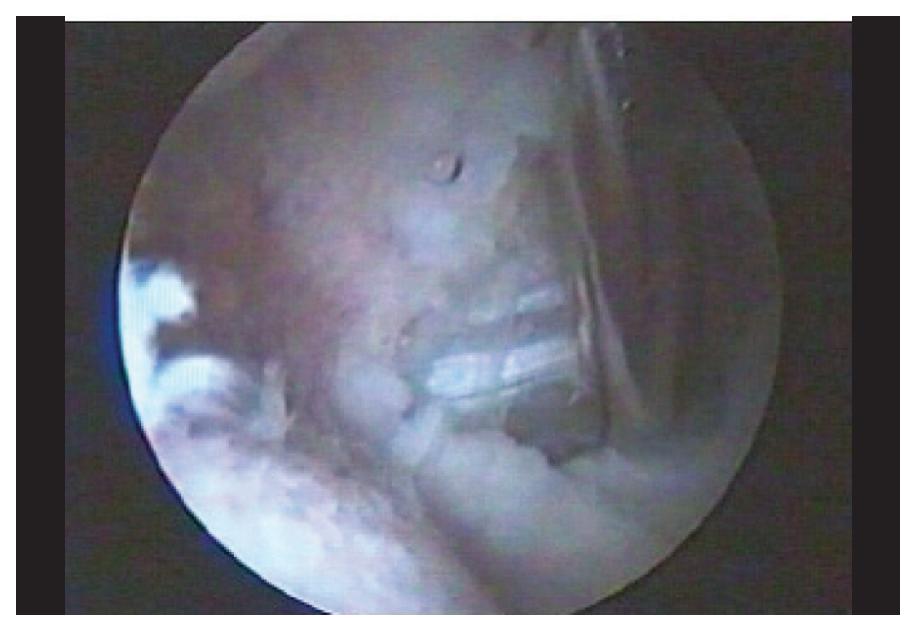

Figure 7 - Snout-like spacer for anterior soft tissue.

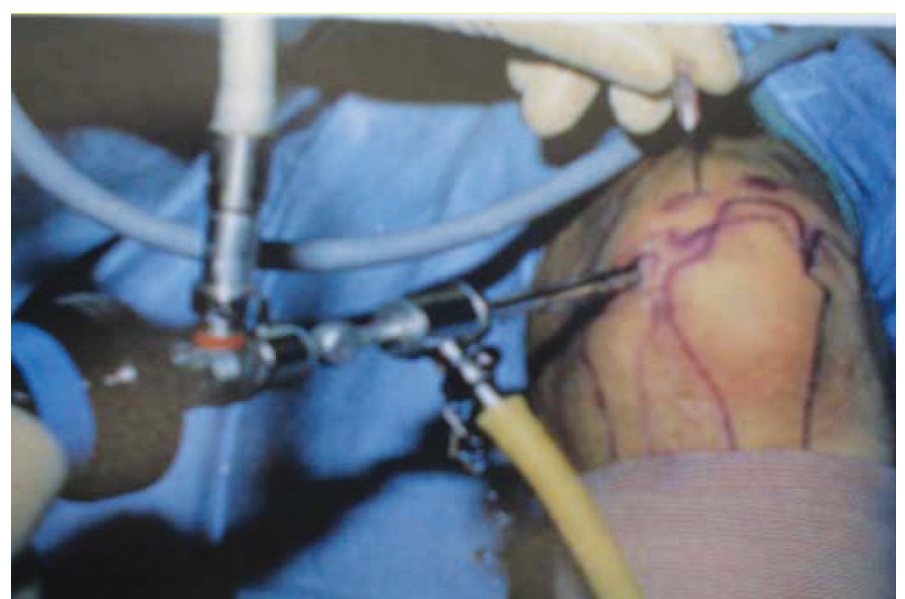

Figure 8 - Construction of posterior portals.

After releasing the elbow stiffness, we left a 3.2 suction drain in two accesses (anterior and posterior; these were removed one day later). Compressive bandaging was applied across the region, and we stimulated early mobility of the operated elbow: as early as possible, i.e. around the second postoperative day.

\section{RESULTS}

The mean postoperative follow-up was 27 months, ranging from four to 37 months (Table 1).

Through using the UCLA scale evaluation method ${ }^{(17)}$, we found good and excellent results in all the cases, with a mean of 33.8 points and range from 31 to 35 points (Table 1).

All the patients were satisfied with the results from the arthroscopic surgical treatment, and their elbows reached a very functional level of ROM.

The amount of gain of elbow joint ROM ranged from $25^{\circ}$ to $55^{\circ}$ (Table 2 ).

There were some complications during the immediate postoperative period, including a case of pain that was unusually strong pain for a minimally invasive procedure and a case of fistula due to accumulation of intra-articular fluid, which was soon resolved, after around two weeks, and did not compromise the final postoperative result.

\section{DISCUSSION}

Various causes may lead to elbow stiffness, such as trauma, free bodies, synovitis or heterotopic ossification, among others ${ }^{(1-4)}$. The great majority of such patients with elbow stiffness acquire this condition through trauma. In our study, this was an absolute finding among our patients.

Different authors agree that if nonsurgical treatment is instituted early on, with physiotherapy and dynamic bracing, for example, it may result in improvement of elbow $\operatorname{ROM}^{(7,8)}$. However, in all cases that we have treated and managed using physiotherapy without surgery, the results achieved for these patients Several surgical techniques are capable of releasing elbow contractures $^{(9-13)}$. Among these, arthroscopic release has been shown to be a truly effective procedure. All the patients in our sample presented good or excellent results, which corroborates our initial affirmation. The arthroscopic technique made it possible to view and treat the associated intra-articular lesions and enabled an early return to activities ${ }^{(18)}$. Because this is a minimally invasive surgical procedure, with consequently less surgical aggression, patients are more quickly able to return to their activities of daily living.

In 1995, Kim et $\mathrm{al}^{(10)}$ demonstrated gains in extension of $7^{\circ}$ and flexion of $17^{\circ}$ after arthroscopic 
treatment of elbow stiffness. In our study, we achieved much greater gains in extension for our patients' elbows (mean gain of $35^{\circ}$ ), with a patient satisfaction rate as good as in the previous paper. However, our results were very similar to those of Aldridge et $\mathrm{al}^{(19)}$, who achieved a mean gain in extension of $37^{\circ}$ for their patients' elbows.

Among the disadvantages and complications of arthroscopic procedures on the elbow, with any treatment aim, the risk of neurovascular lesions while constructing the portals is one of the most feared ${ }^{(19)}$. Seeking to minimize the risks of this procedure, we also made a point of following the guidance of Gallay et $\mathrm{al}^{(20)}$. These authors evaluated the intra-articular volumetric capacity of the elbow and suggested that for clinical purposes, capsule distention using around
$15 \mathrm{ml}$ of fluid was recommendable, with the aim of avoiding risks to the joint capsule and neurovascular structures. Fortunately, all the complications that appeared in our patients were temporary and did not leave any trail of sequelae.

\section{CONCLUSION}

Arthroscopic treatment for elbow stiffness was shown to be a technique with low surgical aggression that was efficient in promoting pain relief, with correction of the deformity and recovery of the ROM over a short space of time.

This is a low-morbidity procedure that is easy to apply after mastering the technique. It constitutes an excellent resource for treating elbow stiffness.

\section{REFERENCES}

1. Glynn JJ, Niebauer JJ. Flexion and extension contracture of the elbow: surgical management. Clin Orthop Relat Res. 1976;(117):289-91.

2. Hoffer MM, Brody G, Ferlic F. Excision of heterotopic ossification about elbows in patients with thermal injury. J Trauma. 1978;18(9):667-70.

3. Nowicki KD, Shall LM. Arthroscopic release of a posttraumatic flexion contracture in the elbow: a case report and review of the literature. Arthroscopy. 1992;8(4):544-7.

4. Andrews JR, Carson WG. Arthroscopy of the elbow. Arthroscopy. 1985;1(2):97-107.

5. Henrikson B. Supracondylar fracture of the humerus in children. A late review of end-results with special reference to the cause of deformity, disability and complications. Acta Chir Scand Suppl. 1966;369:1-72.

6. Wedge $\mathrm{JH}$, Robertson DE. Displaced fractures of the neck of the radius in children. J Bone Joint Surg Br. 1982;64:256.

7. Green DP, McCoy H. Turnbuckle orthotic correction of elbow-flexion contractures after acute injuries. J Bone Joint Surg Am. 1979;61(7):1092-5.

8. Hepburn GR, Crivelli KJ. Use of elbow dynasplint for reduction of elbow flexion contractures: a case study. J Orthop Sports Phys Ther. 1984;5(5):269-74.

9. Morrey BF. Post-traumatic contracture of the elbow. Operative treatment, including distraction arthroplasty. J Bone Joint Surg Am. 1990;72(4):601-18.

10. Kim SJ, Kim HK, Lee JW. Arthroscopy for limitation of motion of the elbow. Arthroscopy. 1995;11(6):680-3.
11. Phillips BB, Strasburger S. Arthroscopic treatment of arthrofibrosis of the elbow joint. Arthroscopy. 1998;14(1):38-44.

12. Kraushaar BS, Nirschl RP, Cox W. A modified lateral approach for release of posttraumatic elbow flexion contracture. J Shoulder Elbow Surg. 1999;8(5):476-80.

13. Morrey BF. Surgical treatment of extraarticular elbow contracture. Clin Orthop Relat Res. 2000;(370):57-64.

14. Willner P. Anterior capsulectomy for contractures of the elbow. J Int Coll Surg. 1948;11(4):359-62.

15. Morrey BF, Askew LJ, Chao EY. A biomechanical study of normal functional elbow motion. J Bone Joint Surg Am. 1981;63(6):872-7.

16. Noojin FK, Savoie FH 3rd, Field LD. Arthroscopic release of the stiff elbow. Tech Shoulder Elbow Surg. 2001;2:17-25.

17. Ellman H, Hanker G, Bayer M. Repair of the rotator cuff. End-result study of factors influencing reconstruction. J Bone Joint Surg Am. 1986;68(8):1136-44.

18. Smith AM, Castle JA, Ruch DS. Arthroscopic resection of the common extensor origin: anatomic considerations. J Shoulder Elbow Surg. 2003;12(4):375-9.

19. Aldridge JM 3rd, Atkins TA, Gunneson EE, Urbaniak JR. Anterior release of the elbow for extension loss. J Bone Joint Surg Am. 2004;86-A(9):1955-60.

20. Gallay SH, Richards RR, O'Driscoll SW. Intraarticular capacity and compliance of stiff and normal elbows. Arthroscopy. 1993;9(1):9-13. 